\title{
Um caso de "Situs viscerum inversus totalis",
}

Delo academico Argemiro Rodrigues de Souza.

0 SITUS inversus totalis, heterotaxia ou inversão total de viceras não é um phenomeno tão raro como de momento se julga.

Quando se falla em inversão total de visceras, a impressão que se tem é a de uma anomalia relativamente rara quer como achado clinico quer como achado anatomo-pathologico.

Entretanto isso não acontece. Si folhearmos os ultimos trabalhos norte-americanos logo apóz a guerra mundial, verificaremos que alguns clinicos, radiologistas e anatomo-pathologistas chegaram a conclusões verdadeiramente instructivas - sobre a frequencia do situs inversus parcialis ou totalis. Assim um observador norte-americano achou a frequencia de 1 para 3.000 em certo grupo examinado durante a grande guerra.

Leon Theodore Le Wald Professor de Roentgenologia da Universidade de New-York, publicou na revista de Chicago de 1925 a seguinte frequencia sobre a inversão splanhnica:

$\begin{array}{clrr}\text { Exames pelos Raios X } & 1 \text { para } & 1.400 \\ , \quad \text { post-mortem } & 1 \text { " } & 5.000 \\ , \quad \text { laboratorios de dissecção } & 1 & , & 10.000 \\ , \quad \text { Physicos } & 1 & & 35.000\end{array}$

Em S. Paulo mesmo tem-se encontrado casos de inversão de viceras alguns até diagnosticados em vida.

Trabalhando no laboratorio de Anatomia Pathologica a cargo co nosso preclaro mestre Dr. Cunha Motta, eu e o dr. Streib Fernandes, anatomo-pathologista do Serviço Sanitario, fomos surprehendidos com a apparição em autopsia de um caso de inversão splanchnica total.

Tem essa autopsia no registro da inspectoria de obitos do "Serviço Sanitario" o numero - SS-241-27.

Tratava-se do cadaver de um individuo, do sexo feminino, com a idade de 84 annos, tendo como causa mortis "arterio sclerose" Ao abrirmos a cavidade abdominal, nossa curiosidade foi desde logo despertada pela posição anomala que occupava o appendice cecal. Este 
se achava collocado na fossa iliaca esquerda; por seu turno o colon sigmoide occupava a fossa iliaca direita; dest'arte o jejuno-ileo tambem deveria assumir uma nova posição e foi o que constatámos. Por seu lado o figado que ultrapassava de dois dedos o rebordo costal, occupava nitidamente o hypochondrio esquerdo, contrahindo relações estreitas com o estomago que tambem mantinha uma posição anormal pois que enchia com os baços e pancreas o hypochondrio direito; aquelles eram em numero de nove sendo tres baços do tamanho de um ovo de gallinha e o menor delles do tamanho de uma cereja, tendo os restantes dimensões intermediarias. Os nove baços agrupavam-se em: una cadeia semelhante ás cadeias ganglionares do apparelho lymphatico.

Ao retirarmos o plastrão sterno-costal notámos incontinente a posição do coração inteiramente opposta á normal; este orgão tinha sua ponta dirigida para a direita; os pulmões seguiam tambem a anormalidade d esituação: o pulmão direito possuia dois lóbos e o esquerdo tres.

As veias cavas attingiam á auricula esquerda e a arteria pulmonar partia doventriculo esquerdo; as veias pulmonares e a aorta estavam em relação com as cavidades direitas; ipso facto, as posições orovalvulares achavam-se igualmente invertidas.

As valvulas não apresentavam lesões denunciando endocardite.

Finalmente, o rim esquerdo descia mais baixo que o direito e isso devido naturalmente á nova posição assumida pelo figado.

Pelo que expuzémos, deprehendemos que essa transposição splanchnica completa não trouxe nenhum obstaculo do cumprimento das funcções por quanto a mulher, attingio em pleno goso de seus direitos vitaes á já invejada idade de 84 annos.

A heterotaxia total comquanto seja uma anomalia grave anatomicamente, não o é phisiologicamente pois não tráz nenhum obstaculo ao cumprimento das funç̧ões e nem tão pouco arrasta a deformidades externas.

\section{CONSIDERAÇÕES EMBRYOGENICAS E TERATOGENESE}

Quando as viceras apparecem no embryão são todas symetricas; as duplas collocadas de cada lado ao plano medindo e as simples divididas em duas metades por esse mesmo plano. Ora, a diversidade de collocação das visceras no adulto provem do que certos orgãos tornam-se impares devido a outra metade ter soffrido atrophia; por outro lado este ou aquelle orgão toma esta ou aquella posição devido ás inflexões diversas que vão assumindo á medida que se desenvolvem.

Assim, desde o inicio o systema arterial dos vertebrados allantodianos apresenta á sahida do coração cinco pares de arcos ou crossas perfeitamente symetricas que em consequencia da atrophia parcial 
dos arcos do lado esquerdo e da desaparição total dos do lado direito, nos conduzem á disposição normal que todos conhecem.

Do mesmo modo o intestino primitivamente um tubo unico situado no plano mediano soffre em se desenvolvendo uma serie de inflexões em virrtude das quaes vem a formar os orgãos asymetricos que constituem a massa intestinal.

Tendo as visceras uma disposição anatomicamente constante o sentido de sua inflexão é invariavel mas sobrevindo a inflexão em sentido inverso, as visceras do lado direito passam para o esquerdo e vice versa observando-se então a hetereotaxia.

Em geral a heterotaxia passa despercebida pois não se oppõe de modo nenhum ao bom funccionamento dos orgãos.

Entretanto parece que isso não se observa em alguns casos quando se trata de inversão parcial, ordinariamente do coração, dand oa cardiopathia congenita.

Interessante foi um caso constatado por Charvet e communicado á Academia em 1847 no qual vio o testiculo direito descer mais baixo que o esquerdo portanto contrario á disposição normal; o autor explica o facto, que na inversão de visceras o figado mudando de posição, o cordão deferente do lado direito torna-se mais longo.

A differença de situação dos rins está em relação com a posição nova do figado. homem.

Segundo Guinard a heterotaxia é mais rara nos animaes que no

Quanto á teratogenese pode-se dizer que, ao par de factos experimentaes que possam comprovar a causa do situs inversus, a questão campeia ainda no terreno das hypothezes sem explicação plausivel.

Já Aristoteles tinha chegado a estudar a inversão nos animaes sem comtudo explicar a sua genese. Do mesmo modo Cornelio Gemma (seculo dezesseis), Alexandre Massaria, Panarali, Antonio Bertrand publicaram trabalhos sobre a heterotaxia.

Giovani Riolano e Winslow sustentaram que a teratogenese do situs inversus escapa completamente a comprehensão theorica.

Entretanto Serres já dizia que as visceras no seu desenvolvimento estão todas subordinadas á posição futura do figado.

Nas mudanças de situação e metamorphose que apresentam, os diversos apparelhos são influenciados pela evolução daquelles que o precederam.

Asim sendo, admitte-se pois que a perturbação de um orgão dominando, pode graças a esta subordinação mutua tornar-se a causa do desvio de todos os orgãos se desenvolvendo depois delle.

O estomago por exemplo provem da modificação de uma parte do intestino primordial; si elle se colloca á esquerda, o cecum deve achar-se á direita; mas quando, em consequencia da inversão o estomago se colloca á direita, o cecum deve desenvolver-se á esquerda. 
Por sua vez o coração apparecendo á principio na parte anterior do tubo neural sob a forma de dois amontoados cellulares chega a constituir um tubo unico antero posterior graças a soldadura dos dois grupos cellulares.

Este tubo se dobra em seguida para a esquerda e sua curvatura se acentuando cada vez mais lhe dá apparencia de um S. que depois de uma serie de transformações attinge emfim ao seu completo desenvolvimento.

Ora, se a inflexão em vez de se fazer para a esquerda se faz para a direita tem-se o ponto de partida de uma inversão visceral.

Esta explicação é do Professor Dareste e é muito acceita.

Em 1883 Herman Foll e Warynski annunciando á Academia de Sciencias que tinham chegado a produzir artificialmente heterotaxia no embryão de frango, deram desta anomalia explicação differente.

Para elles a passagem da symetria embryonaria á asymetria normal, não está sob a dependencia do desvio de tal ou qual orgão que arrastaria uma mudança de posição das outras partes; seria devida sim a uma desigualdade geral e muito precoce do desenvolvimento ao qual escapariam só os orgãos que conservam uma symetria perfeita depois do final de seu desenvolvimento. $\mathrm{O}$ crescimento sendo normalmente mais rapido em toda metade esquerda do embryão, Herman Foll e Warynski procuraram provocar um movimento inverso em diminuindo artificialmente o deenvolvimento desta metade.

Por isto, depois de ter trepanado a casca de ovo em incubação, elles submeteram o lado esquerdo do aro embryonario á acção de um calor irradiante capaz de modificar a vitalidade dos tecidos sem os destruir.

Constataram então que para obter uma inversão total e completa é preciso tomar um embryão de trinta e seis horas e aquecer o lado da extremidade anterior deste embryão de maneira á attingir o blastema esquerdo do coração. Operando sobre o aro pellucido de um embryão de 48 horas notaram que na producção da inversão, o coração invertido é secundario, o que não está de accordo com a explicação de Dareste. Concluindo, para Foll e Warynski a causa da inversão reside na mudança de rapidez no desenvolvimento do corpo, rapidez essa mais accentuada á esquerda que a direita e cujo phenomeno inverso viria provocar a heterotaxia.

Le Wald diz que duplos monstros, duplos gemeos e transposição de visceras tem uma relação intima.

Morrill diz que no desenvolvimento normal a direcção de crescimento tomada pelo figado determina o plano de asymetria.

Spemman e Pressler sustentam que os factores controllando a asymetria estão localisados no primitivo intestino de maneira arranjado tal que, o intestino no normal desenvolvimento, encurva-se primeiro para a esquerda forçando o figado acrescer para a direita. 
As experiencias de Pressler são muito instructivas, pois chegou aquelle autor a provocar por uma manobra do intestino o situs inversus no "Bombinator"

Emfim a questão da teratogenese da inversão de visceras permanece ainda obscura apezar da fonte riquissima de conhecimentos que podemos colher da Embryogenia.

Laboratoire des Produits "Usines du Rhone" 21 RUE JEAN GOUJON - PARIS

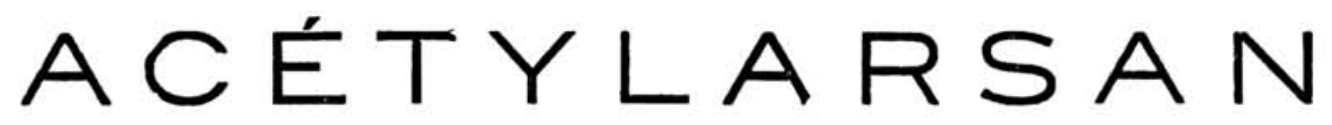
(OXYACETYLAMINA PHENYLARSINATO DE DIETHYLAMINA) TRATAMENTO DA SYPHILIS

1.0 Actividade IGUal a DOS ARSENO-BENZÓES

2. Tolerancia Perfeita
3.0 R A PIDEZ DE A C Ç $\tilde{A} O$ $4 .^{\circ}$ - Facilidade de emprego POR INJECÇÕES INTRAMUSCULARES INDOLARES

Amostras e litteratura aos Medicos mediante pedidos AOS CONCESSIONARIOS ESCLUSIVOS

Companhia Chimica Rhodia Brasileira OAIXA POSTAL 1329

S. PA ULO 